\title{
Cold-Induced RNA-Binding Protein Promotes Glucose Metabolism and Reduces Apoptosis by Increasing AKT Phosphorylation in Mouse Skeletal Muscle Under Acute Cold Exposure
}

Yang Liu ${ }^{\dagger}$, Peng Liu ${ }^{\dagger}$, Yajie Hu, Yu Cao, Jingjing Lu, Yuying Yang, Hongming Lv, Shuai Lian, Bin $\mathrm{Xu}{ }^{*}$ and Shize $\mathrm{Li}^{*}$

National Experimental Teaching Demonstration Center of Animal Medicine Foundation, College of Animal Science and Veterinary Medicine, Heilongjiang Bayi Agricultural University, Daqing, China

OPEN ACCESS

Edited by: Adelino Sanchez Ramos da Silva University of São Paulo, Brazil

Reviewed by: John Henderson, Northumbria University, United Kingdom Michael Mathai,

Victoria University, Australia

${ }^{*}$ Correspondence:

Bin Xu

xubin@byau.edu.cn

Shize Li

byndlsz@163.com

${ }^{t}$ These authors have contributed equally to this work

Specialty section:

This article was submitted to

Cellular Biochemistry,

a section of the journal

Frontiers in Molecular Biosciences

Received: 16 April 2021 Accepted: 13 July 2021 Published: 29 July 2021

Citation:

Liu Y, LiU P, Hu Y, Cao Y, Lu J, Yang Y, Lv H, Lian S, Xu B and LiS (2021) ColdInduced RNA-Binding Protein Promotes Glucose Metabolism and Reduces Apoptosis by Increasing AKT Phosphorylation in Mouse Skeletal Muscle Under Acute Cold Exposure.

Front. Mol. Biosci. 8:685993.

doi: 10.3389/fmolb.2021.685993
The main danger of cold stress to animals in cold regions is systemic metabolic changes and protein synthesis inhibition. Cold-induced RNA-binding protein is a cold shock protein that is rapidly up-regulated under cold stimulation in contrast to the inhibition of most proteins and participates in multiple cellular physiological activities by regulating targets. Therefore, this study was carried out to investigate the possible mechanism of CIRP-mediated glucose metabolism regulation and survival promotion in skeletal muscle after acute cold exposure. Skeletal muscle and serum from mice were obtained after 0, 2, 4 and $8 \mathrm{~h}$ of acute hypothermia exposure. Subsequently, the changes of CIRP, metabolism and apoptosis were examined. Acute cold exposure increased energy consumption, enhanced glycolysis, increased apoptosis, and up-regulated CIRP and phosphorylation of AKT. In addition, CIRP overexpression in $\mathrm{C} 2 \mathrm{C} 12$ mouse myoblasts at each time point under $37^{\circ} \mathrm{C}$ and $32^{\circ} \mathrm{C}$ mild hypothermia increased AKT phosphorylation, enhanced glucose metabolism, and reduced apoptosis. CIRP knockdown by siRNA interference significantly reduced the AKT phosphorylation of $\mathrm{C} 2 \mathrm{C} 12$ cells. Wortmannin inhibited the AKT phosphorylation of skeletal muscle after acute cold exposure, thereby inhibiting glucose metabolism and aggravating apoptosis. Taken together, acute cold exposure up-regulates CIRP in mouse skeletal muscle, which regulates glucose metabolism and maintains energy balance in skeletal muscle cells through the AKT signaling pathway, thus slowing down the apoptosis of skeletal muscle cells.

Keywords: CIRP, glucose metabolism, apoptosis, acute cold exposure, Akt

\section{INTRODUCTION}

A low-temperature environment is a common and unavoidable stressor for humans and livestock in cold regions. Such environments affect neuroendocrine, immune, reproductive, and cardiovascular systems, and cause oxidative stress and apoptosis (Solianik et al., 2014; Cong et al., 2018; Lian et al., 2018). Acute cold exposure cause metabolic disorders, such as increased systemic energy expenditure and increased energy utilization in peripheral tissues (Hao et al., 2015; Yao et al., 2018). Low temperature also has a negative effect on the meat quality and muscle properties (Ferretti, 1992; Short, 2019). Skeletal muscle plays an essential role in the thermogenic metabolic induced by cold 
exposure due to its ability to produce shivering and non-shivering thermogenesis (Haman, 2006; Brychta and Chen, 2017). Glucose conversion is mostly mediated by skeletal muscle metabolic activation during cold exposure (Blondin et al., 2015), and the maintenance of glucose under cold exposure is of great significance for animal survival (Shibata et al., 1989; Labbé et al., 2015).

When mammals suffer from cold exposure resulting in hypothermia, most protein synthesis is inhibited because the cellular process is usually in cell preservation rather than cell growth (Zhu et al., 2016). However, there are a few proteins that increase in contrast to the general decrease in protein synthesis (Hao et al., 2015), and these include RNA-binding motif protein three and cold-induced RNA-binding protein (CIRP) (Shi et al., 2019; Zhu et al., 2019; Linders et al., 2020). CIRP is a highly conserved RNA binding nucleoprotein with an arginine glycine rich domain and an RNA recognition motif. CIRP mainly regulates the transcription and processing of RNA in the nucleus, and the translation and transformation of mRNA in the cytoplasm (Zhu et al., 2016; Zhong and Huang, 2017). CIRP participates in multiple cell physiological activities through its regulation of targets (Xia et al., 2012), for example, cell survival, proliferation, circadian rhythm regulation, telomere maintenance, tumor formation and development (Zhong and Huang, 2017; Indacochea et al., 2021; Kübler et al., 2021). CIRP expression has been detected in various tissues and cells, especially in mild hypothermia (Liu et al., 2019), hypoxia (Wellmann et al., 2004), UV radiation (Sun et al., 2018), heat stress (Nishiyama et al., 1998), endoplasmic reticulum stress (Khan et al., 2017), and oxidative stress (De Leeuw et al., 2007), where its expression is up-regulated and respond to a variety of stress conditions by changing its expression and regulating mRNA stability through its binding site on the $3^{\prime}$-UTR of its targeted mRNAs (Zhong and Huang, 2017; Zhong et al., 2021). There is interest among researchers with regard to the protective effect of CIRP on the body in cold environments; thus, it is also known as a cold shock protein. CIRP is involved in the physiological regulation of hibernation in amphibians (Sugimoto and Jiang, 2008). CIRP links skin temperature with metabolism and defense mechanisms through AMPK (Higashitsuji et al., 2020). Meanwhile, CIRP plays an irreplaceable role in the cryoprotection and in the treatment of brain injury (Saito et al., 2010; Li et al., 2015; Alkabie and Boileau, 2016). CIRP increase the phosphorylation of protein kinase B (AKT) under mild hypothermia (Li et al., 2015), and AKT signaling can regulate nutrient uptake and metabolism through a variety of downstream targets (Manning and Toker, 2017). In addition, activation of CIRP inhibited apoptosis of neural stem cells during mild hypothermia (Saito et al., 2010).

Therefore, we speculate that CIRP plays a protective role by regulating AKT to participate in glucose metabolism of skeletal muscle under acute cold exposure. Then, this study was carried out to obtain strong evidence to support this conjecture.

\section{MATERIALS AND METHODS}

\section{Animals and Acute Cold Exposure}

Male ICR mice weighing 30-32 g and aged 8 weeks were selected as experimental animals in this study. The mice were divided into four groups: a normal temperature control group, and 2, 4, and $8 \mathrm{~h}$ cold exposure groups ( 8 mice per group). The mice were first adapted for 7 days in a phytotron, with groups of five mice in standard polystyrene cages. Each cage contained $200 \mathrm{~g}$ of soft sawdust bedding, and the bedding was changed twice a week. Mice were free to drink water but food intake was limited (from 8: 00 p.m. to 8:00 a.m.). Feeding temperature was set at $28 \pm 0.5^{\circ} \mathrm{C}$, humidity was $40 \pm 5 \%$, illumination intensity was 200 lux, and the light-dark cycle ratio was 12/12 (turn on the lights at 8:00 a.m., turn off the lights at 8:00 p.m.). During the adaptive feeding period, the mice were grabbed for $10 \mathrm{~min}$ each day to adapt to capture by the experimenter.

At the end of adaptive feeding, the normal temperature control group remained at $28^{\circ} \mathrm{C}$. The cold exposure groups were exposed to $4^{\circ} \mathrm{C}$ for 2,4 , and $8 \mathrm{~h}$. The mice were anesthetized with ether and euthanized by cervical dislocation. Blood and gastrocnemius muscle samples were collected.

\section{Biochemical Indices}

Fasting blood glucose in mice was determined by a biochemical analyzer with a test strip (IDEXX Laboratories, United States). Insulin and glucagon levels were determined by an ELISA kit (\#CEA448Mu and CEB266Mu, Cloud-Clone Corp., United States). Fructose-1,6-diphosphate (FDP) and pyruvic acid (PA) contents in skeletal muscle tissue were determined using assay kits (\#BC2240 and BC2200, Solarbio, China).

\section{Periodic Acid Schiff Staining}

The gastrocnemius muscle was fixed with $4 \%$ paraformaldehyde. The samples were routinely dehydrated, embedded in paraffin and $5 \mu \mathrm{m}$ thick sections were prepared. The sections were stained by Periodic Acid Schiff (PAS) stain to examine the glycogen content of gastrocnemius tissues (PAS kit, \#G1281, Solarbio, China).

\section{Western Blotting Analysis}

The equivalent protein in gastrocnemius samples from each group was separated by SDS-PAGE, and electrotransferred to a PVDF membrane (\#IPVH00010, Millipore, Germany). The PVDF membrane was immersed in $10 \mathrm{ml}$ of Ponceau staining solution and shaken for $5 \mathrm{~min}$. After the clear band appeared, each lane was preserved by Chemidoc XRS Gel Imaging System and analyzed by ImageJ software. Then, the membranes were sealed in the blocking buffer for $1 \mathrm{~h}$ at ordinary temperature, and incubated with the primary antibodies overnight at $4^{\circ} \mathrm{C}$ with shaking. This was followed by incubation with the secondary antibody for $1 \mathrm{~h}$ at ordinary temperature. The membranes were visualized by chemiluminescence detection using Luminata Crescendo Western HRP substrate (WBLUR0100, Millipore, Germany). Blots were preserved by the Chemidoc XRS Gel Imaging System and analyzed by ImageJ software.

Antibodies used were as follows: AKT (\#90272, 1:1,000), 6phosphofructo-2-kinase/fructose-2,6-biphosphatase 2 (PFKFB2) (\#13045, 1:1,000), phospho-AKT $\left(\mathrm{Ser}^{473}\right)$ (\#12694, 1:1,000), phospho-PFKFB2 (Ser ${ }^{483}$ ) (\#13064, 1:1,000), phospho-glycogen synthase kinase-3 $\beta$ (GSK3 $\beta)\left(\mathrm{Ser}^{9}\right)(\# 9323,1: 1,000)$, glycogen synthase (GS) (\#3886, 1:1,000) and phospho-GS (Ser ${ }^{641}$ ) (\#3891, 
TABLE 1 | CIRP siRNA sequence.

\begin{tabular}{|c|c|c|}
\hline Name & Sense & Antisense \\
\hline CIRP siRNA\#1 & 5'-GCAGGUCUUCUCCAAGUAUTT-3' & 5'-AUACUUGGAGAAGACCUGCTT-3' \\
\hline CIRP siRNA\#2 & 5'-GGCUAUGAAUGGGAAGUCUTT-3' & 5'-AGACUUCCCAUUCAUAGCCTT-3' \\
\hline CIRP siRNA\#3 & 5'-GGUCCUACAGAGACAGCUATT-3' & 5'-AGACUUCCCAUUCAUAGCCTT-3' \\
\hline NC siRNA & 5'-UUCUCCGAACGUGUCACGUTT-3 & 5'-ACGUGACACGUUCGGAGAATT-3' \\
\hline
\end{tabular}

1:1,000) were purchased from Cell Signaling Technology (United States); glucose transporter-4 (Glut-4) (\#ab654, 1: 2000), CIRP (\#ab166779,1:17,000) and GSK3 $\beta$ (\#ab32391, 1: $8,000)$ were purchased from Abcam (United Kingdom); Bcl-2 assaciated $\mathrm{x}$ protein (Bax) (\#60267-1-lg, 1:2000), B-cell lymphoma-2 (Bcl-2) (\#60178-1-lg, 1:2000), Cleaved Caspase-3 (\#66470-2-lg, 1:500), and $\nabla$-tubulin (\#11224-1-AP, 1:2000) were purchased from Proteintech (United States). Secondary antibodies were labeled with horseradish peroxidase goat antimouse IgG (\#SA00001-1, 1:20,000) and goat anti-rabbit IgG (\#SA00001-2, 1:20,000), which were also purchased from Proteintech (United States).

\section{Cell Culture}

The mouse myoblast cell line $(\mathrm{C} 2 \mathrm{C} 12)$ was purchased from Shanghai Cell Bank of the Chinese Academy of Sciences. High glucose DMEM (Gibco, \#C11995500BT, United States) containing $10 \%$ fetal bovine serum (Gibco, \# 10,099, United States), $100 \mathrm{U} / \mathrm{mL}$ penicillin and streptomycin (Solarbio, \#P1400, China) was used to culture C2C12 cells in a cell incubator at $37^{\circ} \mathrm{C}$ with $5 \% \mathrm{CO}_{2}$.

\section{Cold-Induced RNA-Binding Protein Overexpressed Cell Line Construction and Mild Hypothermia Treatment}

The CIRP overexpression lentivirus was obtained from Beijing Hesheng Gene Technology Co., Ltd. (Beijing, China). The virus were diluted with the appropriate multiplicity of infection (200:1) and mixed with polybrene transfection enhancer (Solarbio, \#H8761). The final polybrene concentration was $6 \mu \mathrm{g} / \mathrm{ml}$, and the mixture was added to each well. Cells were again routinely cultured and replaced with conventional medium $24 \mathrm{~h}$ later. The efficiency of lentivirus infection was detected by fluorescence microscopy $72 \mathrm{~h}$ later. Wildtype cells, empty vector virus-infected cells, and CIRP overexpressed cells were treated with mild hypothermia for 2,4 , and $8 \mathrm{~h}$. The temperature of mild hypothermia treatment was set at $32^{\circ} \mathrm{C}$ according to our previous body surface temperature measurement and in vitro cold exposure model (Liu et al., 2019).

\section{Cold-Induced RNA-Binding Protein siRNA Interference}

CIRP siRNA was obtained from Shanghai Sangon Bioengineering Co., Ltd. (Shanghai, China). All siRNA sequences were shown in Table 1. An appropriate number of cells were seeded on a 6-well plate $24 \mathrm{~h}$ before transfection, and transfected when the cell confluence rate reached $70-80 \%$. PBS washed the cells several times after discarding previous cell medium. $1.9 \mathrm{ml}$ pure DMEM medium was added to the 6-well plate. CIRP siRNA and lipofectamine 2000 (\#11668030, Invitrogen, United States) were mixed thoroughly with serum-free medium of $50 \mu \mathrm{L}$ Opti-MEM (Gibco, \# 11058021, United States), respectively. After standing for $5 \mathrm{~min}$, the two compounds were fully mixed and stood for $20 \mathrm{~min}$ again. Then, $100 \mu \mathrm{L}$ of the mixture was added to the cells after combining CIRP siRNA and lipofectamine 2000, gently shaken and mixed, and then conventionally cultured. The final content of siRNA was 100 pmol per well, and the final content of Lipofectamine 2000 was $12.5 \mu \mathrm{L}$ per well. Cells from the cold exposure group after $72 \mathrm{~h}$ of transfection were placed in the cell incubator at $32^{\circ} \mathrm{C}$ and $5 \% \mathrm{CO}_{2}$ for $4 \mathrm{~h}$, and then total protein was extracted.

\section{AKT Inhibitor Injection and Cold Exposure Treatment}

The following three groups were set up: the control group, DMSO injection group, and wortmannin injection group (8 mice in each group). Wortmannin was dissolved in DMSO and injected intraperitoneally at the dose of $0.5 \mathrm{mg} / \mathrm{kg}$ according to the body weight of mice; In the DMSO injection group, DMSO was injected intraperitoneally at the same dose as the negative control. One hour after the injection of wortmannin, the three groups were exposed at $4^{\circ} \mathrm{C}$ for $4 \mathrm{~h}$. After cold exposure, gastrocnemius muscle samples were collected.

\section{Statistical Analysis}

All data are showed as the mean \pm SEM and were analyzed with GraphPad Prism. Comparisons between groups were performed by one-way ANOVA followed by Tukey's post-hoc test. Statistical significance was assumed at $p<0.05$.

\section{RESULTS}

\section{Effects of Acute Cold Exposure on Energy Metabolism in Mice}

To assess the effect of acute cold exposure on glucose metabolism in mice, serum glucose, insulin, and glucagon levels in all the groups were measured. Serum glucose was significantly decreased after $8 \mathrm{~h}$ of cold exposure $(p<0.05)$, although in the cold exposure group, glucose increased slightly at $2 \mathrm{~h}$ and decreased at $4 \mathrm{~h}$, but no significant difference was observed (Figure 1A). This small increase may have been the result of active mobilization of the body against cold exposure. In addition, the changes in glucagon and insulin during acute cold exposure were also investigated, as these are antagonistic 

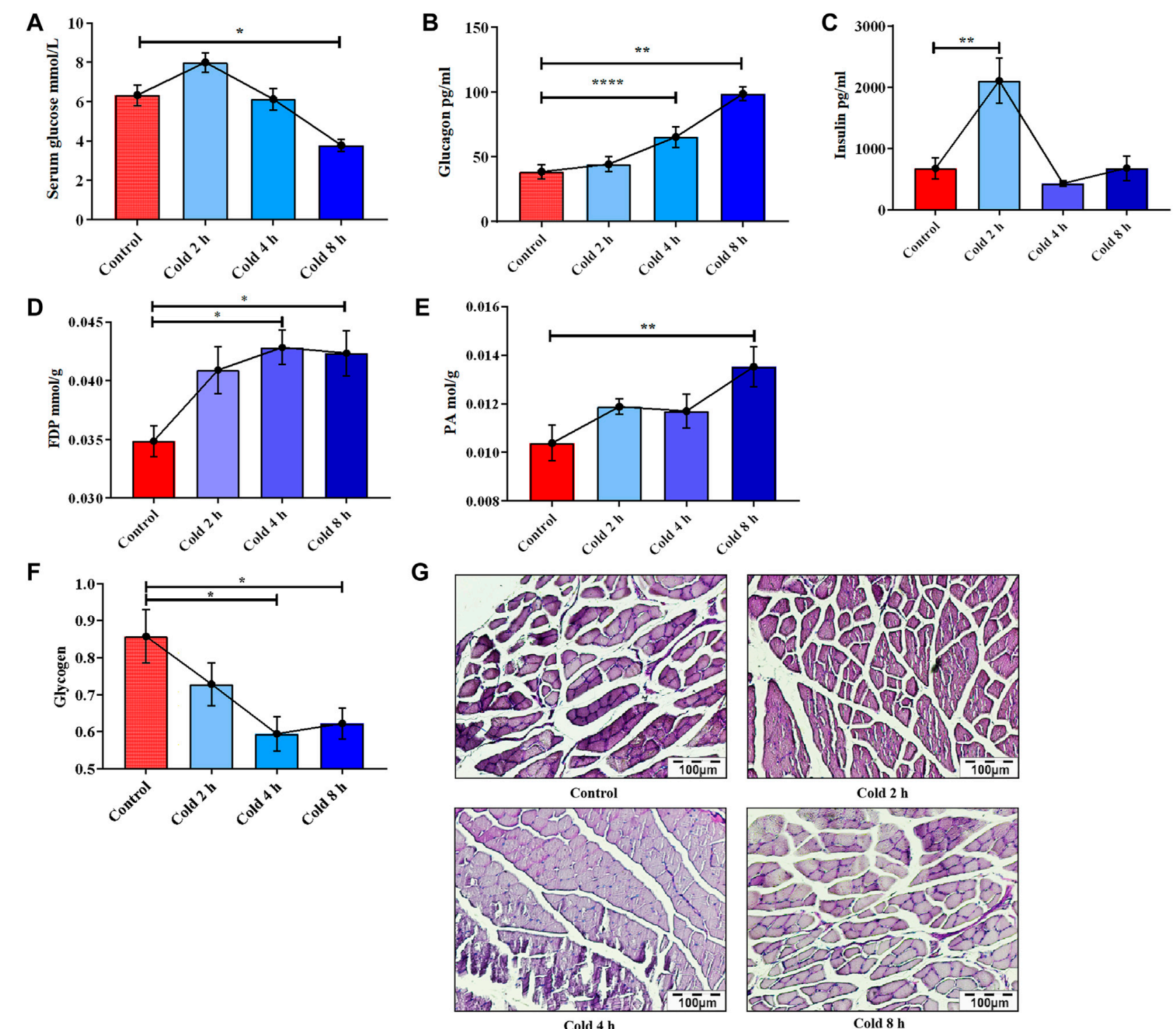

FIGURE 1 | Changes of glucose metabolism induced by acute cold exposure in mice. Effect of acute cold exposure on serum glucose level (A), glucagon level (B), insulin level (C) in mice. Effect of acute cold exposure on FDP level (D) and PA level (E) in the skeletal muscles of mice. Effects of acute cold exposure on glycogen level (F, G) in skeletal muscle of mice. The data are presented as the mean \pm SEM $(n=8)$. Statistically significant differences are indicated; ${ }^{*} p<0.05$, ${ }^{\star *} p<0.01$. FDP, fructose1,6-diphosphate; PA, pyruvic acid.

hormones in regulating blood glucose levels. Glucagon level in the cold exposure group was increased at 4 and $8 \mathrm{~h}(p<0.01)$ (Figure 1B). Insulin level fluctuated with prolongation of acute cold exposure (Figure 1C).

It was also found that acute cold exposure enhanced glycolysis of skeletal muscle in mice. This finding is supported by changes in the glycolytic intermediate fructose 1,6-diphosphate (FDP) and the final product PA. FDP content in skeletal muscle significantly changed with acute cold exposure (Figure 1D), as did pyruvic acid (PA) (Figure 1E). PAS staining results demonstrated that the glycogen of skeletal muscle was decreased in a time-dependent manner (Figures 1F,G), suggesting that acute cold exposure caused glycogen depletion in mouse skeletal muscle.

\section{Acute Cold Exposure Up-Regulated Cold-Induced RNA-Binding Protein, Activated AKT and Enhanced Glucose Metabolism}

In order to examine the mechanism of energy metabolism regulation by CIRP under acute cold exposure, CIRP, AKT and glucose metabolism-related proteins were determined. The results showed that CIRP was up-regulated with prolongation of acute cold exposure in a time-dependent manner (Figure 2B). Acute cold exposure subsequently increased AKT phosphorylation at $\mathrm{Thr}^{308}$ (Figure 2C). The phosphorylation levels of GSK3 $\beta$ and PFKFB2 were enhanced by acute cold 

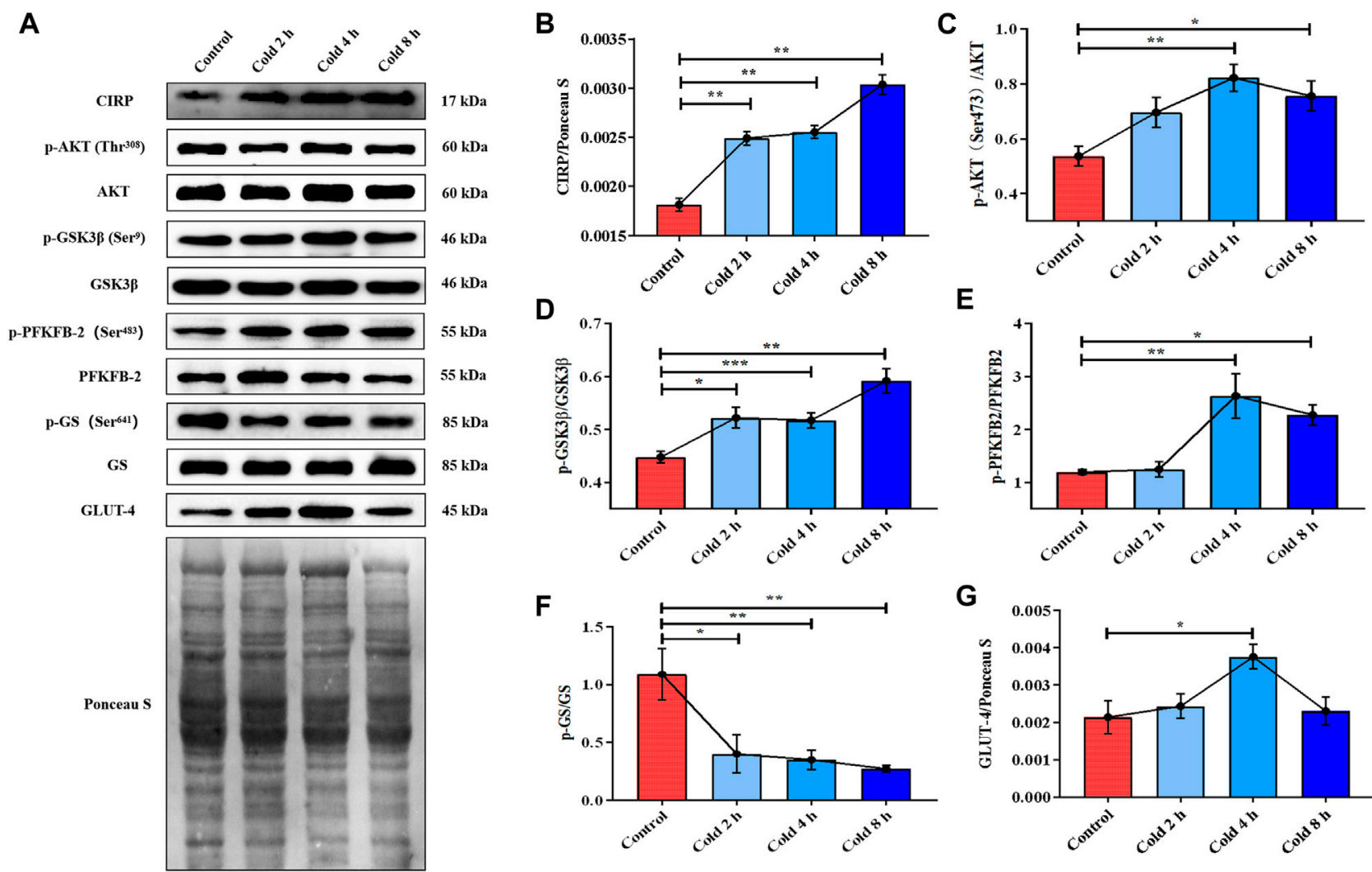

$\mathbf{E}$
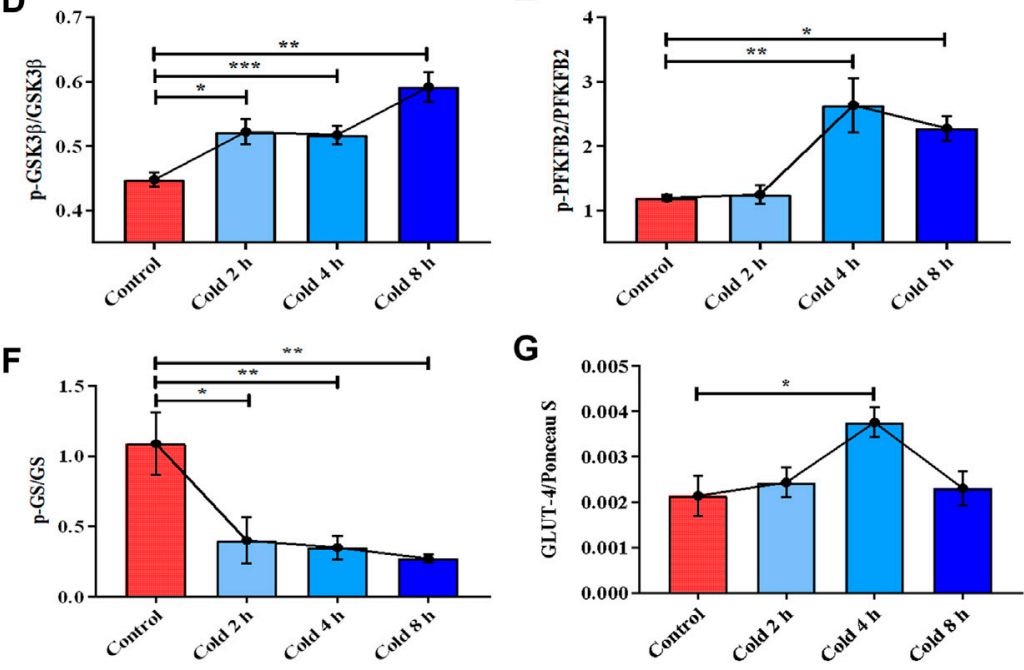

FIGURE 2 | Acute cold exposure up-regulated the expression of CIRP, activated AKT and enhanced glucose metabolism in skeletal muscle of micehanges of glucose metabolism induced by acute cold exposure in mice. (A) Western blotting results of glucose metabolism related proteins in mouse skeletal muscle after acute cold exposure. The protein expression levels and phosphorylation status of CIRP (B), AKT (C), GSK3 $\beta$ (D), PFKFB2 (E), GS (F) and GLUT-4 (G) in the skeletal muscles of mice. The data are presented as the mean \pm SEM $(n=8)$. Statistically significant differences are indicated; ${ }^{*} p<0.05,{ }^{* \star} p<0.01$. CIRP, cold inducible RNA-binding

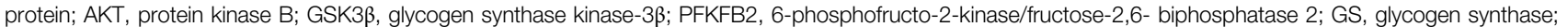
GLUT-4, glucose transporter-4.

exposure (Figures 2D,E). GLUT4 in the cold exposure group was increased (Figure 2F), but GS and its phosphorylation were inhibited in a time-dependent manner (Figure 2G).

\section{Acute Cold Exposure Induced Apoptosis in Skeletal Muscle in Mice}

In order to examine the effect of acute cold exposure on apoptosis in skeletal muscle, Cleaved Caspase-3, Bax and Bcl-2 in mouse skeletal muscle during acute cold exposure were detected. The $\mathrm{Bcl}-2$ protein family plays an important role in endogenous apoptosis pathway through the interaction of anti-apoptotic and pro-apoptotic proteins within the family (Adams and Cory, 2007). Bcl-2 and Bax belong to anti-apoptotic and proapoptotic proteins of the Bcl-2 family, respectively (Peña-Blanco and García-Sáez, 2018). Therefore, the balance between Bcl-2 and Bax can be used as a molecular switch on the apoptotic signaling pathway to determine the direction of cell survival or apoptosis (Leibowitz and $\mathrm{Yu}, 2010$ ). And the up-regulation of Bcl-2/Bax ratio was used as an indicator of apoptosis inhibition. Cleaved Caspase- 3 in the cold exposure group did not change significantly
(Figure 3B), while the ratio of Bcl-2 to Bax increased in varying degrees (Figure 3C).

\section{Overexpression of Cold-Induced \\ RNA-Binding Protein Enhanced AKT \\ Phosphorylation and the Downstream Glucose Metabolism Signaling Pathway} Regulated by AKT Under Mild Hypothermia

In order to further verify our hypothesis, we used the CIRP lentivirus to infect $\mathrm{C} 2 \mathrm{C} 12$ mouse myoblasts, and successfully obtained CIRP overexpression in vitro (Figures 4A-C). CIRP increased over time in all groups under mild hypothermia at $32^{\circ} \mathrm{C}$ (Figures 4B,C). When $\mathrm{C} 2 \mathrm{C} 12$ cells were infected with CIRP lentivirus, CIRP at the indicated time points was significantly increased (Figures 4B,C).

Subsequently, we detected the expression of the AKT signal pathway and phosphorylation of AKT, GSK3 $\beta$, PFKFB2 and GS. Mild hypothermia enhanced the phosphorylation levels of AKT, GSK3 $\beta$ and PFKFB2 (Figures 5B-D). The expression level of GLUT4 under 

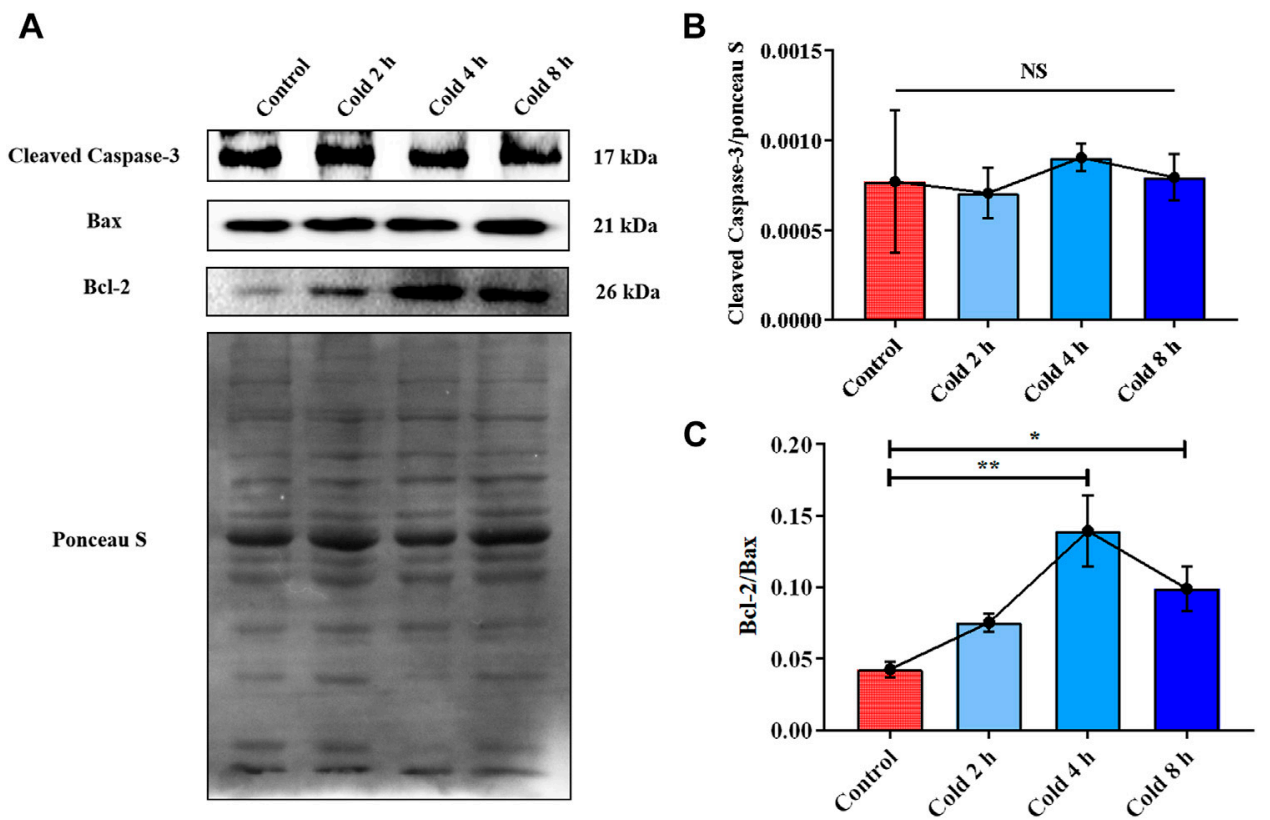

FIGURE 3 | Acute cold exposure induced apoptosis of skeletal muscle in mice. (A) Western blotting results of apoptosis related proteins in mouse skeletal muscle after acute cold exposure. The protein expression levels of Cleaved Caspase-3 (B), the expression ratio of Bax and Bcl-2 (C) in the skeletal muscles of mice. The data are presented as the mean \pm SEM $(n=8)$. Statistically significant differences are indicated; ${ }^{\star} p<0.05,{ }^{* *} p<0.01$. Bax, Bcl-2 assaciated $x$ protein; Bcl-2, B-cell lymphoma-2.

mild hypothermia was increased (Figure 5F), but GS and its phosphorylation were inhibited (Figure 5E). More importantly, overexpression of CIRP significantly increased AKT, GSK3 $\beta$ and PFKFB2 and their phosphorylation (Figures 5B-D), as well as the expression of GLUT4 (Figure 5F), while GS and its phosphorylation were inhibited at $37^{\circ} \mathrm{C}$ and $32^{\circ} \mathrm{C}$ (Figure 5E).

\section{Overexpression of Cold-Induced RNA-Binding Protein Attenuates Apoptosis of C2C12 Cells Under Mild Hypothermia}

To evaluate the effects of mild hypothermia and CIRP overexpression on apoptosis of $\mathrm{C} 2 \mathrm{C} 12$ cells, the changes of Cleaved Caspase-3, Bcl-2and Bax were analyzed. Mild hypothermia increased Cleaved Caspase-3 (Figure 6B) and the ratio of Bcl-2 to Bax (Figure 6C). Cleaved Caspase-3 was significantly decreased, while the ratio of $\mathrm{Bcl}-2$ to $\mathrm{Bax}$ was significantly elevated at $37^{\circ} \mathrm{C}$ or $32^{\circ} \mathrm{C}$ (Figures $6 \mathrm{~B}, \mathrm{C}$ ).

\section{Cold-Induced RNA-Binding Protein Knockdown Reduces AKT and Its Phosphorylation Levels}

In order to verify the regulatory effect of CIRP on AKT under mild hypothermia, we first successfully constructed a CIRP knockdown model using CIRP siRNA\#2 interference (Figures 7A,B). CIRP protein expression was significantly reduced, leading to a significant decrease in AKT phosphorylation (Figures 7C,D).

\section{AKT and Its Phosphorylation Are Essential for Promoting Glucose Metabolism and Reducing Apoptosis of Skeletal Muscles in Mice Exposed to Acute Cold Exposure}

To confirm the function of AKT regulated by CIRP in promoting glucose metabolism and reducing apoptosis in skeletal muscle in mice during acute cold exposure, we treated the mice injected with wortmannin (a classic inhibitor of the AKT pathway) under $4 \mathrm{~h}$ of acute cold exposure, then determined the expression and phosphorylation levels of AKT and downstream glucose metabolism proteins. The cold exposure for $4 \mathrm{~h}$ was due to the more interesting changes in CIRP and AKT in the body under this time node. The AKT phosphorylation was significantly decreased after injection of wortmannin (Figure 8B), which reduced the levels of GSK3 $\beta$, PFKFB2 and their phosphorylation, and GLUT4 (Figures 8C-E).

In addition, Cleaved Caspase- 3 was significantly elevated (Figure 9B), and the expression ratio of $\mathrm{Bcl}-2$ to $\mathrm{Bax}$ was significantly decreased after wortmannin injection (Figure 9C).

\section{DISCUSSION}

Hypothermia is an environment that imposes high energy demands. Therefore, exposure to a cold environment can cause serious systemic metabolic disorders, such as increased utilization of energy in peripheral tissues, increased systemic energy consumption, and increased glucose production in the liver (Hao et al., 2015; Yao et al., 2018). These changes in energy 


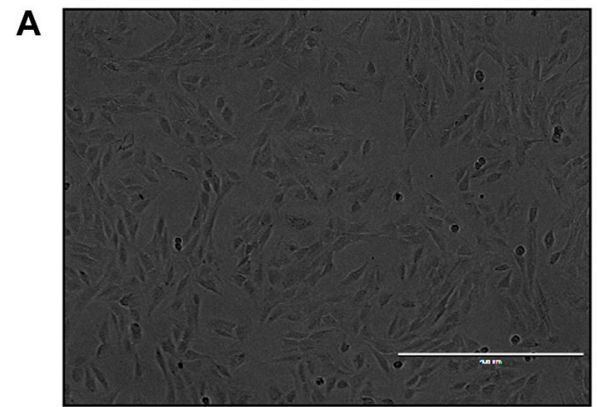

Blank

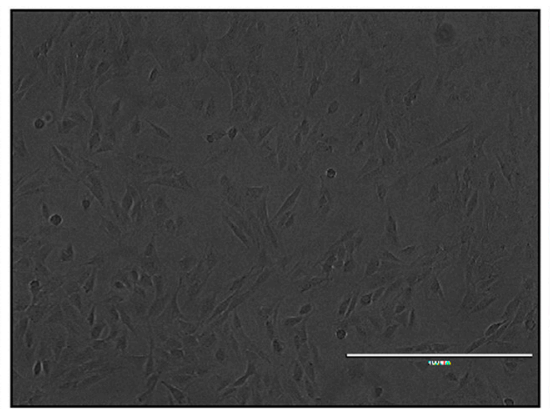

Control lentivirus empty vector

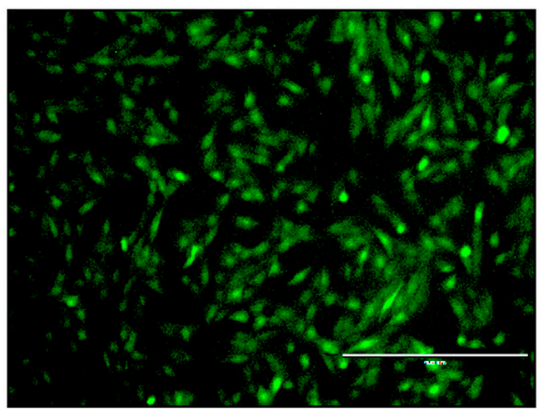

CIRP overexpression lentivirus

B

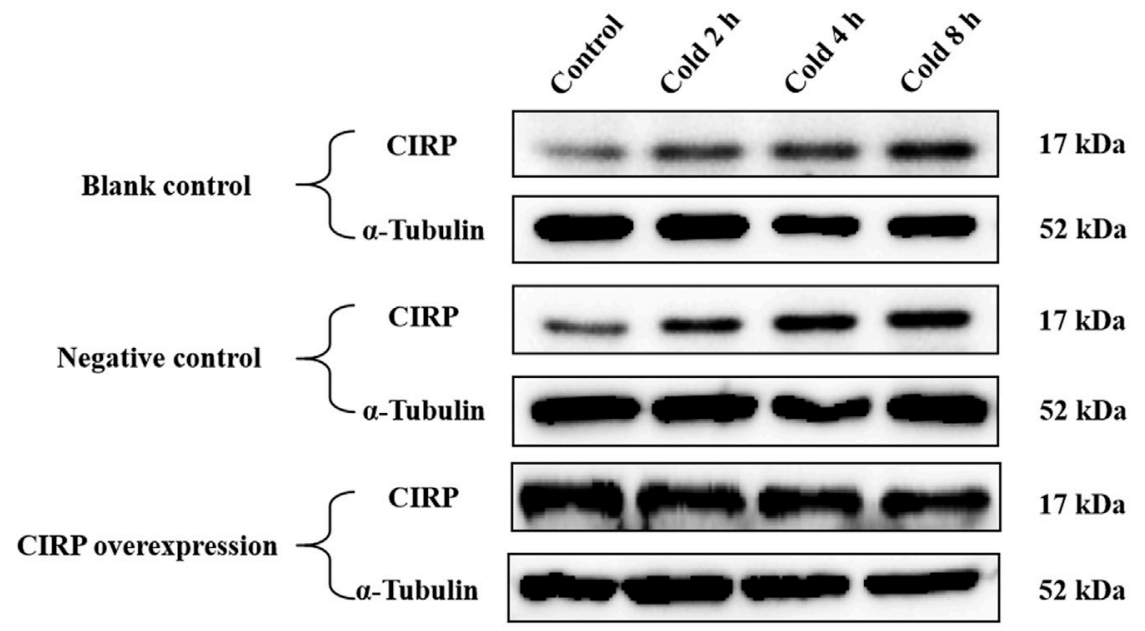

C

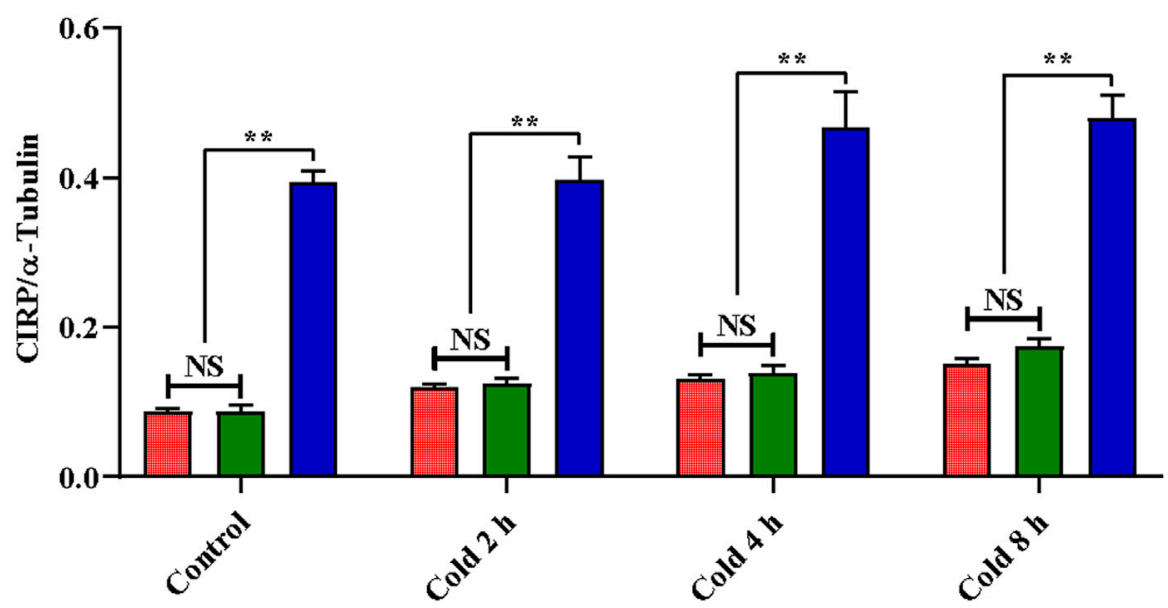

Blank control

$\square$ Negative control

CIRP overexpression

FIGURE 4 | Establishment of CIRP overexpression and its expression changesunder mild hypothermia in $\mathrm{C} 2 \mathrm{C} 12$ cells. (A) Observation of $\mathrm{C} 2 \mathrm{C} 12$ cells infected with CIRP lentivirus for 72 hours by fluorescence microscope. (B, C) Effects of mild hypothermia and lentivirus infection on CIRP protein expression in C2C12 cells. The data are presented as the mean \pm SEM $(n=8)$. Statistically significant differences are indicated; ${ }^{*} p<0.05,{ }^{* *} p<0.01$. CIRP, cold inducible RNA-binding protein.

metabolism are mainly used for cold-induced thermogenesis to maintain the body temperature of thermostatic animals (Brychta and Chen, 2017). Fatty acids are the main energy source in cold-induced thermogenesis, but glucose is essential (Labbé et al., 2015). There is also evidence that glucose is conducive to maintaining an elevated fatty acid oxidation rate during cold exposure (Shibata et al., 1989). The homeostasis of blood glucose level during cold exposure is very important to ensure the energy supply and survival of various tissues (Vallerand et al., 1990; Wang and Wahl, 2014). Results have shown that the blood glucose level decreased significantly in the late stage of acute cold exposure, which 


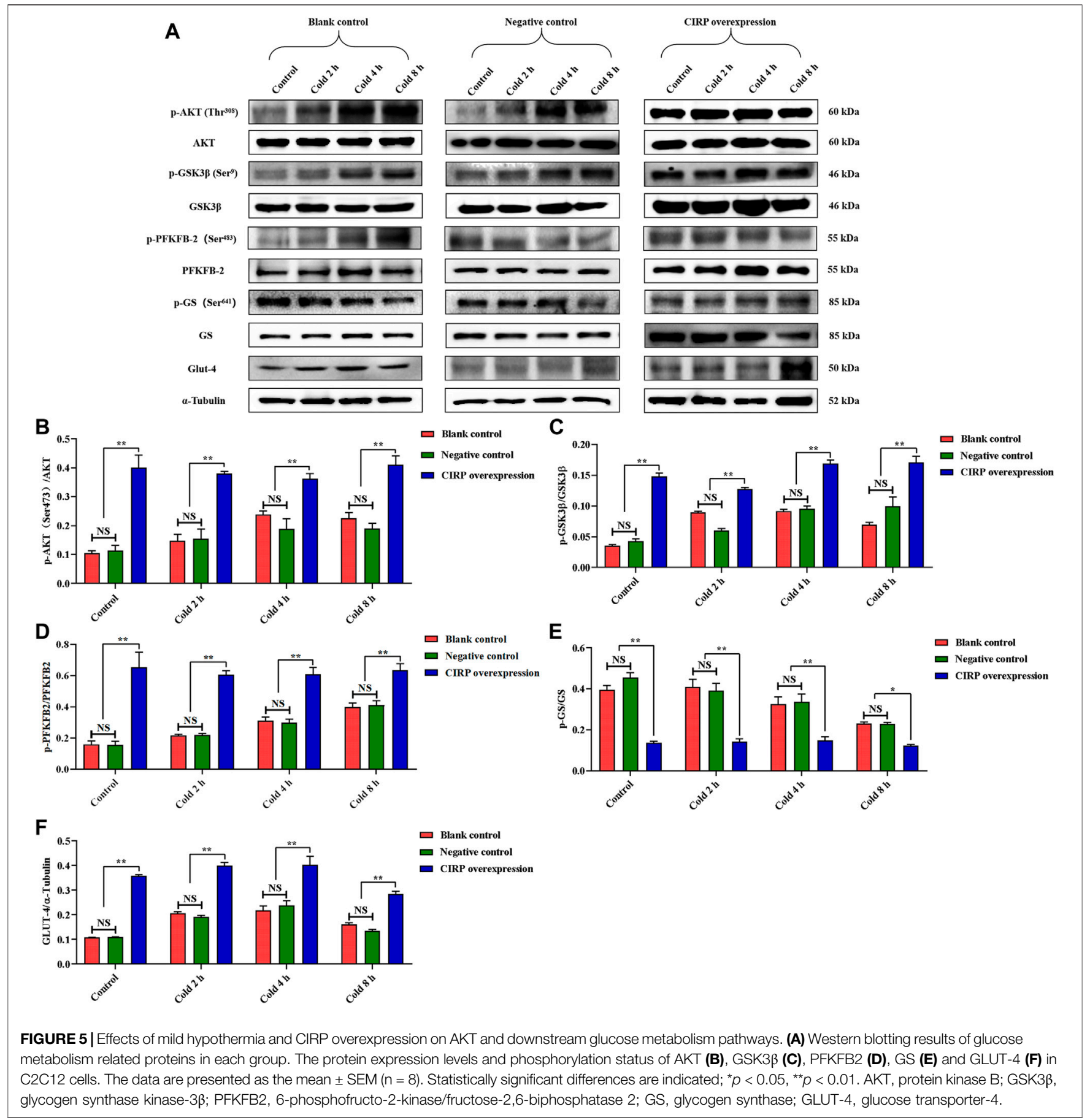

further proved that acute cold exposure affected the changes in energy metabolism and the increased utilization and uptake of glucose in peripheral tissues. Our results showed that glucagon levels remained stable at the beginning of acute cold exposure and then increased continuously. However, insulin levels increased at the beginning of acute cold exposure, and then fluctuated. Insulin and glucagon act synergistically to regulate the production and utilization of blood glucose to maintain normal levels (Sharabi et al., 2015). Glucagon can promote glycogen decomposition and gluconeogenesis to meet the body's energy needs in nutritional deficiency (Sharabi et al., 2015). This is the main reason for the continuous increase in glucagon with prolongation of acute cold exposure. One of the bases of glucose homeostasis is the dynamic regulation of insulin secretion according to compensatory nutritional or metabolic changes. The irregular changes in insulin level may be caused by rapid energy mobilization and consumption due to cold stress. 

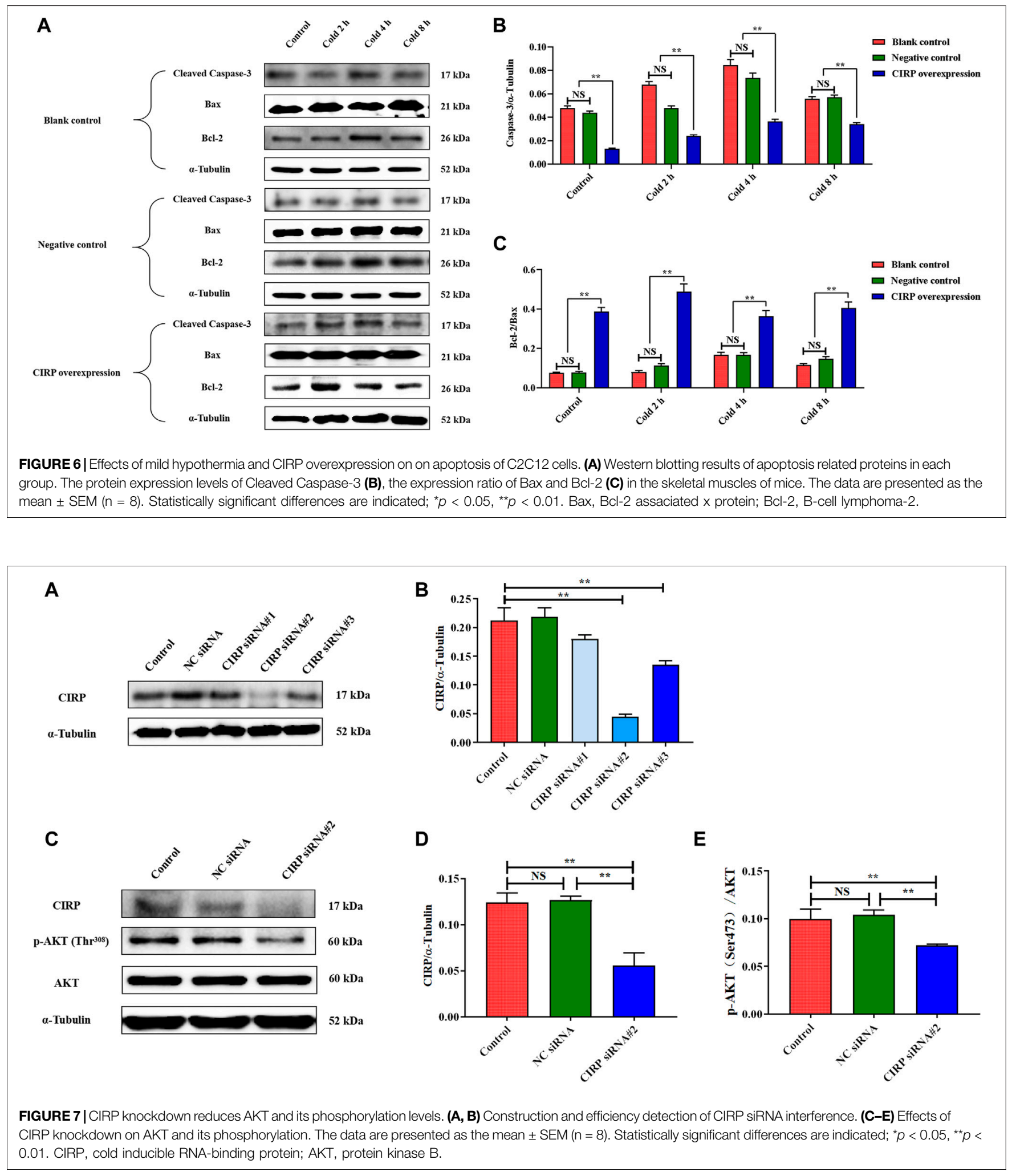

Glucose uptake induced by shivering contraction of skeletal muscle depends mainly on GLUT4 (Huang and Czech, 2007; Richter and Hargreaves, 2013). GLUT4 changed in a sequential manner with prolongation of acute cold exposure time, further indicating that glucose uptake in skeletal muscle increased after cold exposure. We found that glycogen content in skeletal muscle 

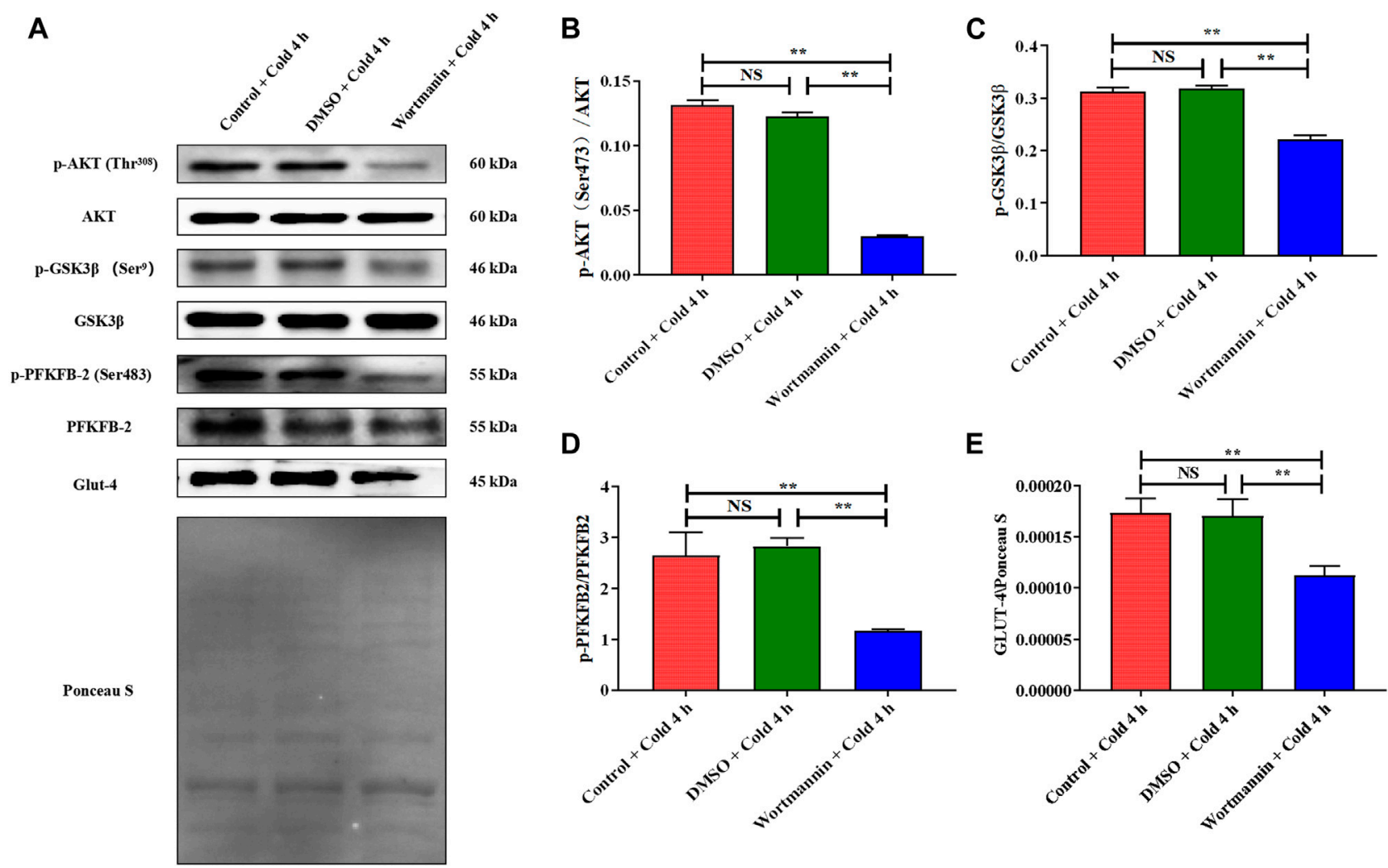

D

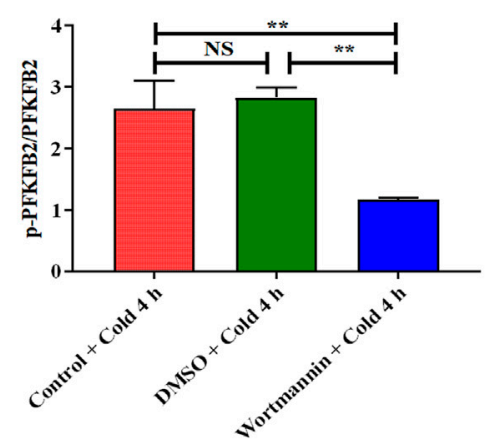

E

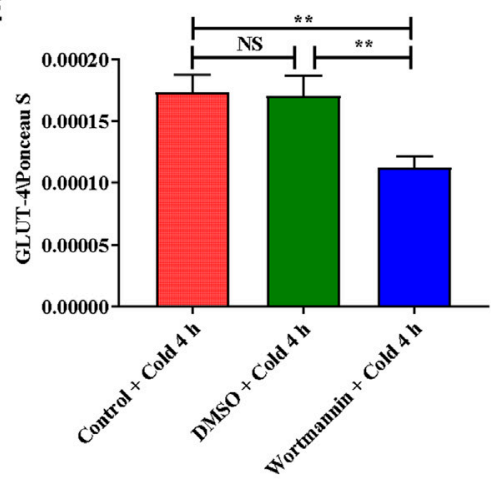

FIGURE 8| The inhibition of AKT results in the decrease of glucose metabolism in skeletal muscle of mice under acute cold exposure. (A) Western blotting results of glucose metabolism related proteins in each group. Effects of wortmannin on protein expression levels and phosphorylation of AKT (B), GSK3 $\beta$ (C), PFKFB2 (D) and GLUT-4 (E) in skeletal muscle of mice after acute cold exposure. The data are presented as the mean \pm SEM $(n=8)$. Statistically significant differences are indicated; ${ }^{*} p<$

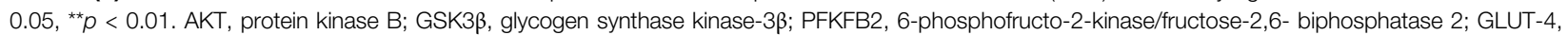
glucose transporter-4.

decreased after acute cold exposure, suggesting that acute cold exposure may promote muscle glycogen consumption and lead to a decrease in glycogen content. In addition, maintenance of muscle glycogen levels depends greatly on the supply of blood glucose by glycogen depletion in the liver. Our previous study also found that acute cold exposure caused a significant decrease in liver glycogen, which is another powerful confirmation of muscle glycogen changes (Liu et al., 2019). We then examined the AKT/ GSK3 $\beta / G S$ pathway, as the above results also indicated that skeletal muscle demonstrates an increased need for skeletal muscle glycogen synthesis during acute cold exposure. GLUT4 acts as a signal to stimulate AKT (Huang and Czech, 2007). The results showed increased phosphorylation of $\mathrm{AKT}$ at $\mathrm{Thr}^{308}$ during acute cold exposure. AKT phosphorylation regulates glycogen synthesis through GSK3 $\beta / G S$ pathway (Doble and Woodgett, 2003). AKT activation phosphorylates and inactivates GSK3 $\beta$, leading to the activation of GS (the ratelimiting enzyme in glycogen synthesis), thereby promoting glycogen synthesis (Henriksen, 2010; Beck-Nielsen, 2012; White et al., 2013). Phosphorylation of AKT and GSK3 $\beta$ in skeletal muscle were increased after acute cold exposure, while the phosphorylation of GS was decreased. Therefore, acute cold exposure activates the main signal pathway of glycogen synthesis in skeletal muscle. The production and destruction of fructose-2, 6-diphosphate is catalyzed by a bifunctional enzyme called PFKFB2. 6-phosphofructokinase-1 is a rate-limiting enzyme for glycolysis, which catalyzes the conversion of fructose-6phosphate to FDP, and its physiological allosteric activator is fructose-2, 6-diphosphate. Therefore, PFKFB2 is regarded as a key regulator of glycolysis (Baillet et al., 2017). We found that the phosphorylation of PFKFB2 at $\mathrm{Ser}^{483}$ was enhanced after acute cold exposure, which indicated that the glycolytic activity in skeletal muscle of mice was enhanced after acute cold exposure. FDP is a metabolic intermediate of glycolysis, which can provide sufficient ATP level, promote the glycolysis process and maintain intracellular calcium balance (Bickler and Kelleher, 1992; Rui, 2014). And the final product of glycolysis is PA. Hence, increased levels of FDP and PA more directly indicate the increase of glycolysis in gastrocnemius muscle of mice after acute cold exposure.

CIRP, as a cold shock protein, is up-regulated and then transferred from the nucleus to the cytoplasm, which responds to cell stress and alleviates stress injury (Yang and Carrier, 2001; De Leeuw et al., 2007). Our previous studies have confirmed that up- 

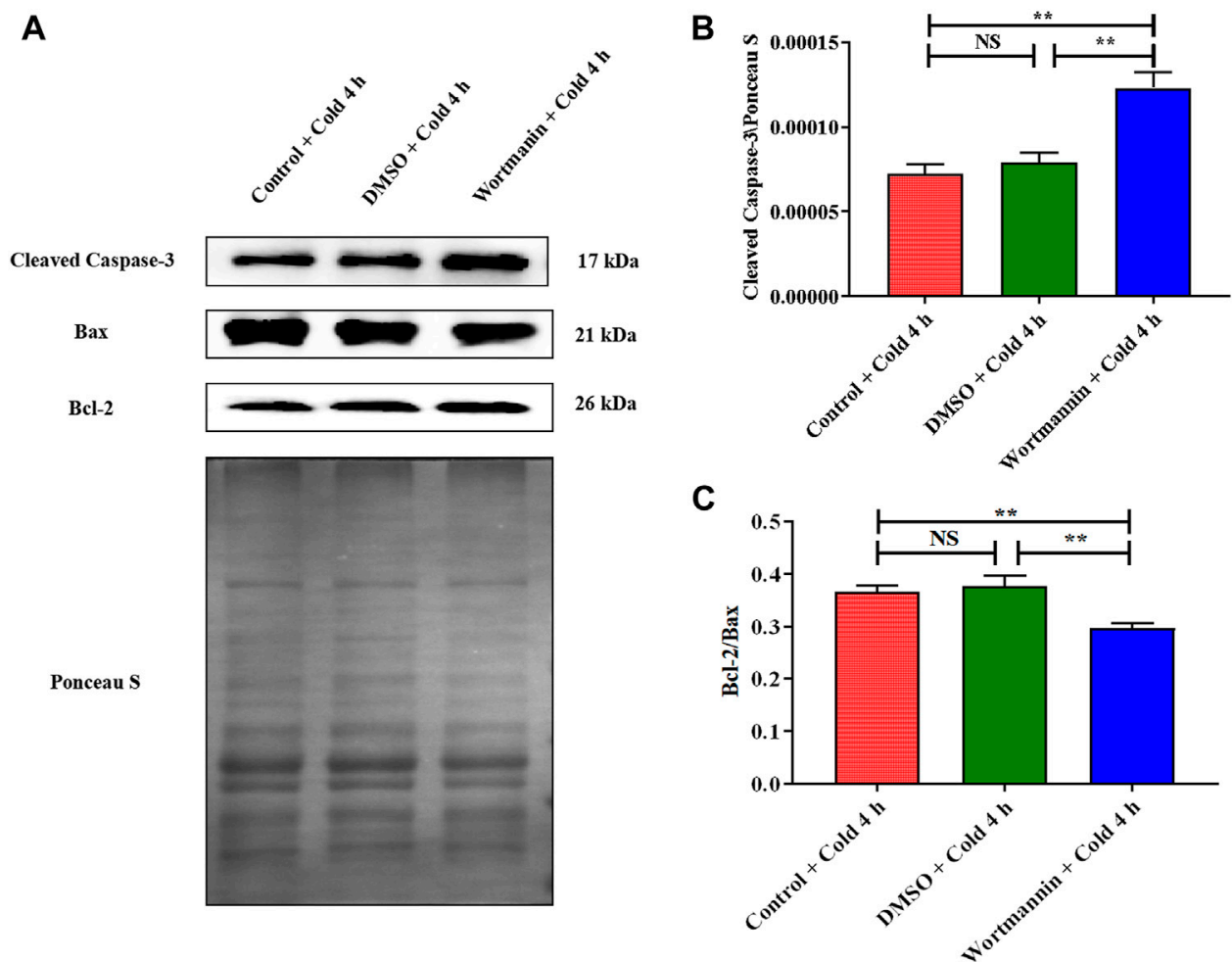

FIGURE 9 | Effect of AKT inhibition on skeletal muscle apoptosis in mice after acute cold exposure. (A) Western blotting results of apoptosis related proteins in each group. The protein expression levels of Cleaved Caspase-3 (B), the expression ratio of Bax and Bcl-2 (C) in the skeletal muscles of mice. The data are presented as the mean \pm SEM $(\mathrm{n}=8)$. Statistically significant differences are indicated; ${ }^{\star} p<0.05,{ }^{\star \star} p<0.01$. Bax, Bcl-2 assaciated $x$ protein; Bcl-2, B-cell lymphoma-2.

regulated CIRP in liver induced by acute cold exposure increases cytoprotection (Liu et al., 2019). Consistent with this, we found that acute cold exposure also up-regulated CIRP in the skeletal muscle of mice and reduced apoptosis of skeletal muscle cells. CIRP participates in multiple signal transduction pathways required for cell function, especially the signal pathways related to apoptosis and proliferation (Zhong and Huang, 2017; Lujan et al., 2018). Cleaved Caspase- 3 is the activated form of caspase3 (Choudhary et al., 2015), and it is also the most important marker for detecting various apoptotic signaling induced apoptosis of cells. We did not observe significant changes in skeletal muscle Cleaved Caspase-3 levels after acute cold exposure. Hypothermia can significantly up-regulate the expression of Bcl-2 in endothelial cells (Sakurai et al., 2013). However, up-regulation of CIRP induced by mild hypothermia inhibits the formation of oxygen free radicals and protects neurons from apoptosis (Li et al., 2015). We also found that acute cold exposure increased Bcl-2, and increased the $\mathrm{Bcl}-2 / \mathrm{Bax}$ ratio. Our evidence shows that CIRP alleviates apoptosis in skeletal muscle tissue during acute cold exposure. In addition, the increase in CIRP in response to acute cold exposure caused similar changes in glucose metabolism and apoptosis in both skeletal muscle and liver of mice (Liu et al., 2019). This not only indicates that CIRP has a general protective effect on regulating glucose metabolism and reducing apoptosis during acute cold exposure, but also suggests that CIRP may cause crosstalk between skeletal muscle and liver to regulate systemic glycogen level. Skeletal muscles secrete a variety of peptides to communicate information with fat, liver, pancreas, bone and brain to respond to environmental/metabolic changes for energy homeostasis (Pedersen and Febbraio, 2012).

Based on the above results, we believe that CIRP promotes glucose metabolism and reduces apoptosis by increasing AKT phosphorylation in the skeletal muscle of mice under mild hypothermia. To clarify the regulatory role of CIRP on the AKT signaling pathway, we subsequently overexpressed and knocked down CIRP in the C2C12 cold exposure model in vitro. The $\mathrm{C} 2 \mathrm{C} 12$ cold exposure model was successfully constructed based on our previous research (Li et al., 2015; Liu et al., 2019). The results of the C2C12 cold exposure model in vitro were basically consistent with those in vivo, which showed that CIRP was up-regulated, AKT was activated, glucose metabolism and anti-apoptotic gene protein expression were increased in C2C12 mouse myoblasts under mild hypothermia. CIRP overexpression increased the phosphorylation of AKT, GSK3 $\beta$, PFKFB2, and GLUT4 protein expression in C2C12 cells at each time point, and inhibited the phosphorylation of $\mathrm{GS}$ at $37^{\circ} \mathrm{C}$ and $32^{\circ} \mathrm{C}$. This is basically consistent with the research that CIRP increased the phosphorylation of AKT and activated the AKT signaling pathway (Liu et al., 2015). Furthermore, the phosphorylation of AKT was significantly decreased with CIRP knockdown. This further proves that CIRP regulates AKT expression and activation. 


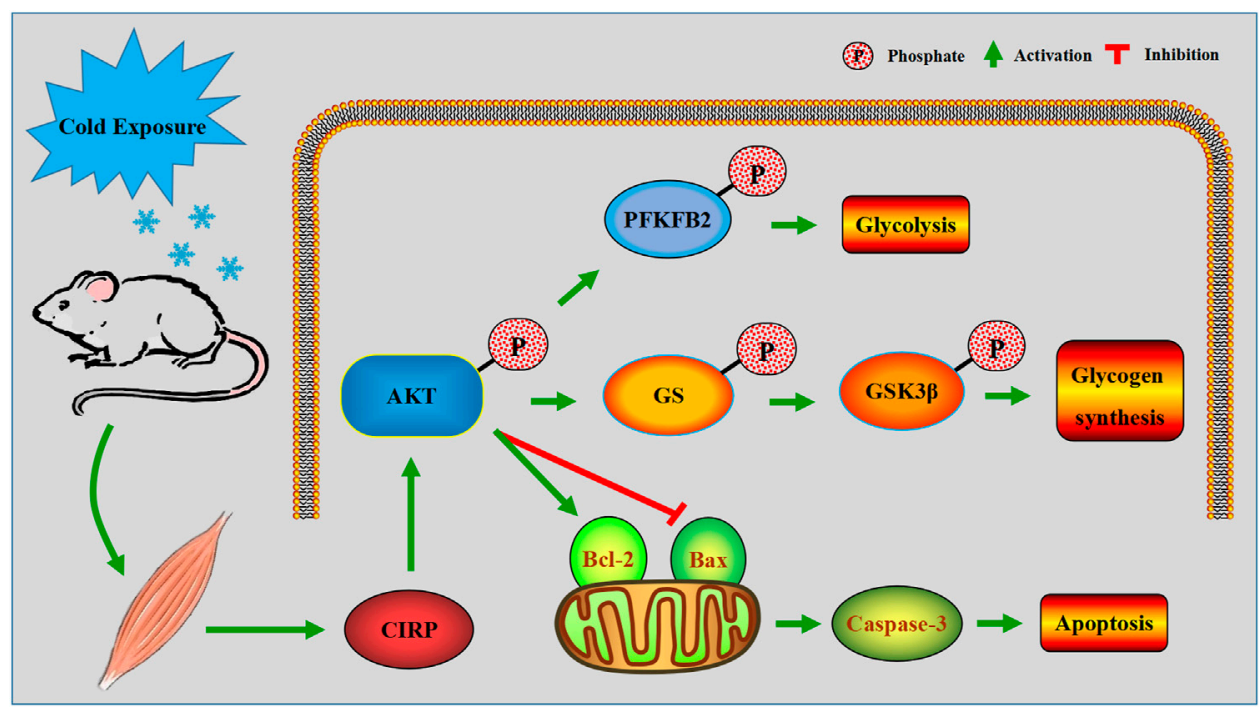

FIGURE 10 | A model of the regulatory mechanism of CIRP in skeletal muscle of mice with acute cold exposure. Arrows indicate promotion, and T-bars indicate inhibition.

AKT is an essential mediator of phosphoinositide 3-kinase in inhibiting apoptosis and promoting cell survival (Feng and Qiu, 2018). AKT acts as an anti-apoptotic agent by inactivating forkhead transcription factors and blocking mitochondrial release of cytochrome C (Goldbraikh et al., 2020). AKT phosphorylation also inactivates Bad and Caspase-9 (Vescovo et al., 2001; Li et al., 2012). Moreover, the AKT signaling pathway increases Bcl-2 and decreases Bax and Cleaved Caspase-3, thereby attenuating TNF- $\alpha$-induced apoptosis ( $\mathrm{Li}$ et al., 2019). On the other hand, GSK3 $\beta$ also promotes apoptosis through a variety of pathways, including p53 acetylation, Bcl-2 degradation, Bax phosphorylation, and/or HSF1 phosphorylation (Doble and Woodgett, 2003; Kockeritz et al., 2006; Kazemi et al., 2010). In addition, inhibition of GSK3 $\beta$ activity through phosphorylation of $\mathrm{Ser}^{9}$ residues helps protect against oxidative stress and promotes cold exposure protection (Wang et al., 2016). CIRP overexpression significantly decreased Cleaved Caspase-3 expression in $\mathrm{C} 2 \mathrm{C} 12$ mouse myoblasts under mild hypothermia, and significantly improved expression of the Bcl2/Bax ratio. These results suggest that CIRP may attenuate mild hypothermia-induced apoptosis of $\mathrm{C} 2 \mathrm{C} 12$ cells through activation of the AKT signaling pathway.

The regulation of CIRP on AKT is fully demonstrated by the overexpression and knockdown of CIRP. We subsequently confirmed the role of the AKT signaling pathway in glucose metabolism and apoptosis in mouse skeletal muscle by the intraperitoneal injection of wortmannin (a classical AKT inhibitor). The AKT signaling pathway regulates glycogen synthesis and glycolysis in C2C12 cells (Park et al., 2016; Yoshida et al., 2017). Inhibition of AKT decreased the expression of GLUT4 and glucose uptake in C2C12 cells (Wang et al., 2017). The results showed that wortmannin significantly decreased AKT phosphorylation and inhibited AKT signaling pathway activity; the downstream GSK3 $\beta$ phosphorylation level was diminished, and the glycogen synthesis was inactivated in skeletal muscle; the phosphorylation level of PFKFB2 was reduced and the glycolytic activity decreased; GLUT4 expression was inhibited and the ability to absorb glucose was weakened in skeletal muscle. Our evidence indicates that $\mathrm{AKT}$ is the main regulatory pathway of glucose metabolism in mouse skeletal muscle during acute cold exposure. In addition, AKT plays a vital role in the regulation of skeletal muscle apoptosis. When inhibited, Cleaved Caspase-3 expression is increased and the level of skeletal muscle cell apoptosis is increased; when activated, Cleaved Caspase-3 expression is decreased, and cell apoptosis is inhibited (Li et al., 2012). Cleaved Caspase- 3 expression was elevated and the ratio of $\mathrm{Bcl}-2$ to Bax was reduced in the skeletal muscle of mice during acute cold exposure. The inhibition of AKT by wortmannin can significantly enhance the activity of the apoptotic signaling pathway in mouse skeletal muscle during acute cold exposure. Therefore, we believe that AKT and its phosphorylation are essential for promoting glucose metabolism and thereby reducing apoptosis in the skeletal muscles of mice with acute cold exposure.

\section{CONCLUSION}

The above results demonstrated that up-regulation of CIRP in mouse skeletal muscle due to acute cold exposure can promote glucose metabolism and reduce apoptosis by activating AKT. The proposed role of CIRP in skeletal muscle of mice during acute cold exposure is illustrated in Figure 10.

\section{DATA AVAILABILITY STATEMENT}

The raw data supporting the conclusions of this article will be made available by the authors, without undue reservation. 


\section{ETHICS STATEMENT}

The animal study was reviewed and approved by Ethics Committee of animal science and Technology College of Heilongjiang Bayi Agricultural University.

\section{AUTHOR CONTRIBUTIONS}

YL wrote the manuscript and had the idea for this study. PL completed the experiments and perfected the experimental design. $\mathrm{YH}$ and JL analyzed all the data and performed a literature search. YY, HL, and SL provided technical support during the

\section{REFERENCES}

Adams, J. M., and Cory, S. (2007). The Bcl-2 Apoptotic Switch in Cancer Development and Therapy. Oncogene 26 (9), 1324-1337. doi:10.1038/ sj.onc. 1210220

Alkabie, S., and Boileau, A. J. (2016). The Role of Therapeutic Hypothermia after Traumatic Spinal Cord Injury-A Systematic Review. World Neurosurg. 86, 432-449. doi:10.1016/j.wneu.2015.09.079

Baillet, A., Hograindleur, M. A., El Benna, J., Grichine, A., Berthier, S., Morel, F., et al. (2017). Unexpected Function of the Phagocyte NADPH Oxidase in Supporting Hyperglycolysis in Stimulated Neutrophils: Key Role of 6phosphofructo-2-kinase. FASEB j. 31 (2), 663-673. doi:10.1096/fj.201600720r

Beck-Nielsen, H. (2012). The Role of Glycogen Synthase in the Development of Hyperglycemia in Type 2 Diabetes - 'To Store or Not to Store Glucose, That's the Question'. Diabetes Metab. Res. Rev. 28 (8), 635-644. doi:10.1002/dmrr.2337

Bickler, P. E., and Kelleher, J. A. (1992). Fructose-1,6-bisphosphate Stabilizes Brain Intracellular Calcium during Hypoxia in Rats. Stroke 23 (11), 1617-1622. doi:10.1161/01.str.23.11.1617

Blondin, D. P., Labbé, S. M., Phoenix, S., Guérin, B., Turcotte, É. E., Richard, D., et al. (2015). Contributions of white and Brown Adipose Tissues and Skeletal Muscles to Acute Cold-Induced Metabolic Responses in Healthy Men. J. Physiol. 593 (3), 701-714. doi:10.1113/jphysiol.2014.283598

Brychta, R. J., and Chen, K. Y. (2017). Cold-induced Thermogenesis in Humans. Eur. J. Clin. Nutr. 71 (3), 345-352. doi:10.1038/ejcn.2016.223

Choudhary, G. S., Al-Harbi, S., and Almasan, A. (2015). Caspase-3 Activation Is a Critical Determinant of Genotoxic Stress-Induced Apoptosis. Methods Mol. Biol. 1219, 1-9. doi:10.1007/978-1-4939-1661-0_1

Cong, P., Liu, Y., Liu, N., Zhang, Y., Tong, C., Shi, L., et al. (2018). Cold Exposure Induced Oxidative Stress and Apoptosis in the Myocardium by Inhibiting the Nrf2-Keap1 Signaling Pathway. BMC Cardiovasc. Disord. 18 (1), 36. doi:10.1186/s12872-018-0748-x

De Leeuw, F., Zhang, T., Wauquier, C., Huez, G., Kruys, V., and Gueydan, C. (2007). The Cold-Inducible RNA-Binding Protein Migrates From the Nucleus to Cytoplasmic Stress Granules by a Methylation-Dependent Mechanism and Acts as a Translational Repressor. Exp. Cel. Res. 313 (20), 4130-4144. doi:10.1016/j.yexcr.2007.09.017

Doble, B. W., and Woodgett, J. R. (2003). GSK-3: Tricks of the Trade for a MultiTasking Kinase. J. Cel. Sci. 116 (Pt 7), 1175-1186. doi:10.1242/jcs.00384

Feng, F.-B., and Qiu, H.-Y. (2018). Effects of Artesunate on Chondrocyte Proliferation, Apoptosis and Autophagy through the PI3K/AKT/mTOR Signaling Pathway in Rat Models with Rheumatoid Arthritis. Biomed. Pharmacother. 102, 1209-1220. doi:10.1016/j.biopha.2018.03.142

Ferretti, G. (1992). Cold and Muscle Performance. Int. J. Sports Med. 13 (Suppl. 1), S185-S187. doi:10.1055/s-2007-1024634

Goldbraikh, D., Neufeld, D., Eid-Mutlak, Y., Lasry, I., Gilda, J. E., Parnis, A., et al. (2020). USP1 Deubiquitinates Akt to Inhibit PI3K-Akt-FoxO Signaling in Muscle during Prolonged Starvation. EMBO Rep. 21 (4), e48791. doi:10.15252/embr.201948791

Haman, F. (2006). Shivering in the Cold: from Mechanisms of Fuel Selection to Survival. J. Appl. Physiol. (1985) 100 (5), 1702-1708. doi:10.1152/ japplphysiol.01088.2005 experiments. SL and BX strictly supervised the whole work and reviewed the data.

\section{FUNDING}

This study was funded by National Natural Science Foundation of China (31972637), Key Program of Natural Science Foundation of Heilongjiang Province (ZD 2019C004), Natural Science Foundation of Heilongjiang Province (YQ2021C050), Heilongjiang Bayi Agricultural University for San Heng San Zong (ZRCQC202003) and Graduate Innovative Research Project of Heilongjiang Bayi Land Reclamation University (YJSCX2021-Z01).

Hao, Q., Yadav, R., Basse, A. L., Petersen, S., Sonne, S. B., Rasmussen, S., et al (2015). Transcriptome Profiling of Brown Adipose Tissue during Cold Exposure Reveals Extensive Regulation of Glucose Metabolism. Am. J. Physiol. Endocrinol. Metab. 308 (5), E380-E392. doi:10.1152/ ajpendo.00277.2014

Henriksen, E. J. (2010). Dysregulation of Glycogen Synthase Kinase-3 in Skeletal Muscle and the Etiology of Insulin Resistance and Type 2 Diabetes. Curr. Diabetes Rev. 6 (5), 285-293. doi:10.2174/157339910793360888

Higashitsuji, H., Fujita, T., Higashitsuji, H., and Fujita, J. (2020). Mammalian ColdInducible RNA-Binding Protein Facilitates Wound Healing through Activation of AMP-Activated Protein Kinase. Biochem. biophysical Res. Commun. 533 (4), 1191-1197. doi:10.1016/j.bbrc.2020.10.004

Huang, S., and Czech, M. P. (2007). The GLUT4 Glucose Transporter. Cel Metab. 5 (4), 237-252. doi:10.1016/j.cmet.2007.03.006

Indacochea, A., Guerrero, S., Ureña, M., Araujo, F., Coll, O., LLeonart, M. E., et al. (2021). Cold-Inducible RNA Binding Protein Promotes Breast Cancer Cell Malignancy by Regulating Cystatin C Levels. Rna 27 (2), 190-201. doi:10.1261/ rna.076422.120

Kazemi, Z., Chang, H., Haserodt, S., McKen, C., and Zachara, N. E. (2010). O-linked $\beta$-N-acetylglucosamine (O-GlcNAc) Regulates Stress-Induced Heat Shock Protein Expression in a GSK-3 $\beta$-dependent Manner. J. Biol. Chem. 285 (50), 39096-39107. doi:10.1074/jbc.m110.131102

Khan, M. M., Yang, W.-L., Brenner, M., Bolognese, A. C., and Wang, P. (2017). Cold-inducible RNA-Binding Protein (CIRP) Causes Sepsis-Associated Acute Lung Injury via Induction of Endoplasmic Reticulum Stress. Scientific Rep. 7 (1), 41363. doi:10.1038/srep41363

Kockeritz, L., Doble, B., Patel, S., and Woodgett, J. (2006). Glycogen Synthase Kinase-3 - an Overview of an Over-achieving Protein Kinase. Curr. Drug Targets 7 (11), 1377-1388. doi:10.2174/1389450110607011377

Kübler, M., Beck, S., Fischer, S., Götz, P., Kumaraswami, K., Ishikawa-Ankerhold, H., et al. (2021). Absence of Cold-Inducible RNA-Binding Protein (CIRP) Promotes Angiogenesis and Regeneration of Ischemic Tissue by Inducing M2like Macrophage Polarization. Biomedicines 9 (4), 395. doi:10.3390/ biomedicines 9040395

Labbé, S. M., Caron, A., Bakan, I., Laplante, M., Carpentier, A. C., Lecomte, R., et al. (2015). In Vivo measurement of Energy Substrate Contribution to Coldinduced Brown Adipose Tissue Thermogenesis. FASEB j. 29 (5), 2046-2058. doi:10.1096/fj.14-266247

Leibowitz, B., and Yu, J. (2010). Mitochondrial Signaling in Cell Death via the Bcl-2 Family. Cancer Biol. Ther. 9 (6), 417-422. doi:10.4161/cbt.9.6.11392

Li, J. H., Zhang, X., Meng, Y., Li, C. S., Ji, H., Yang, H. M., et al. (2015). [Cold Inducible RNA-Binding Protein Inhibits Hippocampal Neuronal Apoptosis under Hypothermia by Regulating Redox System]. Sheng Li Xue Bao 67 (4), 386-392. doi:10.13294/j.aps.2015.0047

Li, M., Ye, J., Zhao, G., Hong, G., Hu, X., Cao, K., et al. (2019). Gas6 Attenuates Lipopolysaccharide-Induced TNF-A expression and Apoptosis in H9C2 Cells through NF-Kb and MAPK Inhibition via the Axl/PI3K/Akt Pathway. Int. J. Mol. Med. 44 (3), 982-994. doi:10.3892/ijmm.2019.4275

Li, W. X., Chen, S. F., Chen, L. P., Yang, G. Y., Li, J. T., Liu, H. Z., et al. (2012). Thimerosal-induced Apoptosis in Mouse C2C12 Myoblast Cells Occurs 
through Suppression of the PI3K/Akt/survivin Pathway. PLoS One 7 (11), e49064. doi:10.1371/journal.pone.0049064

Lian, S., Wang, D., Xu, B., Guo, W., Wang, L., Li, W., et al. (2018). Prenatal Cold Stress: Effect on Maternal hippocampus and Offspring Behavior in Rats. Behav. Brain Res. 346, 1-10. doi:10.1016/j.bbr.2018.02.002

Linders, J., Madhi, R., Rahman, M., Mörgelin, M., Regner, S., Brenner, M., et al. (2020). Extracellular Cold-Inducible RNA-Binding Protein Regulates Neutrophil Extracellular Trap Formation and Tissue Damage in Acute Pancreatitis. Lab. Invest. 100 (12), 1618-1630. doi:10.1038/s41374-020-0469-5

Liu, J., Xue, J., Zhang, H., Li, S., Liu, Y., Xu, D., et al. (2015). Cloning, Expression, and Purification of Cold Inducible RNA-Binding Protein and its Neuroprotective Mechanism of Action. Brain Res. 1597, 189-195. doi:10.1016/j.brainres.2014.11.061

Liu, P., Yao, R., Shi, H., Liu, Y., Lian, S., Yang, Y., et al. (2019). Effects of Cold-Inducible RNA-Binding Protein (CIRP) on Liver Glycolysis during Acute Cold Exposure in C57BL/6 Mice. Int. J. Mol. Sci. 20 (6), 1470. doi:10.3390/ijms20061470

Lujan, D. A., Ochoa, J. L., and Hartley, R. S. (2018). Cold-inducible RNA Binding Protein in Cancer and Inflammation. Wiley Interdisciplinary Reviews. RNA 9 (2), 1462. doi:10.1002/wrna.1462

Manning, B. D., and Toker, A. (2017). AKT/PKB Signaling: Navigating the Network. Cell 169 (3), 381-405. doi:10.1016/j.cell.2017.04.001

Nishiyama, H., Danno, S., Kaneko, Y., Itoh, K., Yokoi, H., Fukumoto, M., et al. (1998). Decreased Expression of Cold-Inducible RNA-Binding Protein (CIRP) in Male Germ Cells at Elevated Temperature. Am. J. Pathol. 152 (1), 289-296.

Park, M., Kaddai, V., Ching, J., Fridianto, K. T., Sieli, R. J., Sugii, S., et al. (2016). A Role for Ceramides, but Not Sphingomyelins, as Antagonists of Insulin Signaling and Mitochondrial Metabolism in C2C12 Myotubes. J. Biol. Chem. 291 (46), 23978-23988. doi:10.1074/jbc.m116.737684

Pedersen, B. K., and Febbraio, M. A. (2012). Muscles, Exercise and Obesity: Skeletal Muscle as a Secretory Organ. Nat. Rev. Endocrinol. 8 (8), 457-465. doi:10.1038/ nrendo.2012.49

Peña-Blanco, A., and García-Sáez, A. J. (2018). Bax, Bak and beyond - Mitochondrial Performance in Apoptosis. FEBS J. 285 (3), 416-431. doi:10.1111/febs.14186

Richter, E. A., and Hargreaves, M. (2013). Exercise, GLUT4, and Skeletal Muscle Glucose Uptake. Physiol. Rev. 93 (3), 993-1017. doi:10.1152/physrev.00038.2012

Rui, L. (2014). Energy Metabolism in the Liver. Compr. Physiol. 4 (1), 177-197. doi:10.1002/cphy.c130024

Saito, K., Fukuda, N., Matsumoto, T., Iribe, Y., Tsunemi, A., Kazama, T., et al. (2010). Moderate Low Temperature Preserves the Stemness of Neural Stem Cells and Suppresses Apoptosis of the Cells via Activation of the Cold-Inducible RNA Binding Protein. Brain Res. 1358, 20-29. doi:10.1016/j.brainres.2010.08.048

Sakurai, T., Kudo, M., Watanabe, T., Itoh, K., Higashitsuji, H., Arizumi, T., et al. (2013). Hypothermia Protects against Fulminant Hepatitis in Mice by Reducing Reactive Oxygen Species Production. Dig. Dis. 31 (5-6), 440-446. doi:10.1159/000355242

Sharabi, K., Tavares, C. D. J., Rines, A. K., and Puigserver, P. (2015). Molecular Pathophysiology of Hepatic Glucose Production. Mol. aspects Med. 46, 21-33. doi:10.1016/j.mam.2015.09.003

Shi, H., Yao, R., Lian, S., Liu, P., Liu, Y., Yang, Y. Y., et al. (2019). Regulating Glycolysis, the TLR4 Signal Pathway and Expression of RBM3 in Mouse Liver in Response to Acute Cold Exposure. Stress 22 (3), 366-376. doi:10.1080/ 10253890.2019 .1568987

Shibata, H., Pérusse, F., Vallerand, A., and Bukowiecki, L. J. (1989). Cold Exposure Reverses Inhibitory Effects of Fasting on Peripheral Glucose Uptake in Rats. Am. J. Physiol. 257 (1 Pt 2), R96-R101. doi:10.1152/ajpregu.1989.257.1.r96

Short, B. (2019). Cold Temperatures Put a Freeze on Myosin Activation. J. Gen. Physiol. 151 (11), 1247. doi:10.1085/jgp.201912509

Solianik, R., Skurvydas, A., Brazaitis, M., and Vitkauskienè, A. (2014). Gender-Specific Cold Responses Induce a Similar Body-Cooling Rate But Different Neuroendocrine and Immune Responses. Cryo Biol. 69 (1), 26-33. doi:10.1016/j.cryobiol.2014.04.015

Sugimoto, K., and Jiang, H. (2008). Cold Stress and Light Signals Induce the Expression of Cold-Inducible RNA Binding Protein (Cirp) in the Brain and Eye of the Japanese Treefrog (Hyla japonica). Comp. Biochem. Physiol. A. Mol. Integr. Physiol. 151 (4), 628-636. doi:10.1016/j.cbpa.2008.07.027

Sun, W., Liao, Y., Yi, Q., Wu, S., Tang, L., and Tong, L. (2018). The Mechanism of CIRP in Regulation of STAT3 Phosphorylation and Bag-1/S Expression upon UVB Radiation. Photochem. Photobiol. 94 (6), 1234-1239. doi:10.1111/php.12981

Vallerand, A. L., Pérusse, F., and Bukowiecki, L. J. (1990). Stimulatory Effects of Cold Exposure and Cold Acclimation on Glucose Uptake in Rat Peripheral
Tissues. Am. J. Physiol. 259 (5 Pt 2), R1043-R1049. doi:10.1152/ ajpregu.1990.259.5.r1043

Vescovo, G., Ambrosio, G. B., and Libera, L. D. (2001). Apoptosis and Changes in Contractile Protein Pattern in the Skeletal Muscle in Heart Failure. Acta Physiol. Scand. 171 (3), 305-310. doi:10.1046/j.1365-201x.2001.00832.x

Wang, L., Zhang, B., Zheng, W., Kang, M., Chen, Q., Qin, W., et al. (2017). Exosomes Derived from Pancreatic Cancer Cells Induce Insulin Resistance in C2C12 Myotube Cells through the PI3K/Akt/FoxO1 Pathway. Scientific Rep. 7 (1), 5384. doi:10.1038/s41598-017-05541-4

Wang, L., Zhang, S., Cheng, H., Lv, H., Cheng, G., and Ci, X. (2016). Nrf2-mediated Liver protection by Esculentoside A against Acetaminophen Toxicity through the AMPK/Akt/GSK3 $\beta$ Pathway. Free Radic. Biol. Med. 101, 401-412. doi:10.1016/j.freeradbiomed.2016.11.009

Wang, X., and Wahl, R. (2014). Responses of the Insulin Signaling Pathways in the Brown Adipose Tissue of Rats Following Cold Exposure. PLoS One 9 (6), e99772. doi:10.1371/journal.pone.0099772

Wellmann, S., Bührer, C., Moderegger, E., Zelmer, A., Kirschner, R., Koehne, P., et al. (2004). Oxygen-regulated Expression of the RNA-Binding Proteins RBM3 and CIRP by a HIF-1-independent Mechanism. J. Cel. Sci. 117 (Pt 9), 1785-1794. doi:10.1242/jcs.01026

White, J. P., Gao, S., Puppa, M. J., Sato, S., Welle, S. L., and Carson, J. A. (2013). Testosterone Regulation of Akt/mTORC1/FoxO3a Signaling in Skeletal Muscle. Mol. Cell. Endocrinol. 365 (2), 174-186. doi:10.1016/j.mce.2012.10.019

Xia, Z., Zheng, X., Zheng, H., Liu, X., Yang, Z., and Wang, X. (2012). Coldinducible RNA-Binding Protein (CIRP) Regulates Target mRNA Stabilization in the Mouse Testis. FEBS Lett. 586 (19), 3299-3308. doi:10.1016/ j.febslet.2012.07.004

Yang, C., and Carrier, F. (2001). The UV-Inducible RNA-Binding Protein A18 (A18 hnRNP) Plays a Protective Role in the Genotoxic Stress Response. J. Biol. Chem. 276 (50), 47277-47284. doi:10.1074/jbc.m105396200

Yao, R., Yang, Y., Lian, S., Shi, H., Liu, P., Liu, Y., et al. (2018). Effects of Acute Cold Stress on Liver O-GlcNAcylation and Glycometabolism in Mice. Int. J. Mol. Sci. 19 (9). doi:10.3390/ijms19092815

Yoshida, K., Imamura, C. K., Hara, K., Mochizuki, M., and Tanigawara, Y. (2017). Effect of Everolimus on the Glucose Metabolic Pathway in Mouse Skeletal Muscle Cells (C2C12). Metabolomics 13 (8), 98. doi:10.1007/s11306-017-1236-5

Zhong, P., and Huang, H. (2017). Recent Progress in the Research of ColdInducible RNA-Binding Protein. Future Sci. OA 3 (4), Fso246. doi:10.4155/fsoa2017-0077

Zhong, P., Peng, J., Yuan, M., Kong, B., and Huang, H. (2021). Cold-inducible RNA-Binding Protein (CIRP) in Inflammatory Diseases: Molecular Insights of its Associated Signalling Pathways. Scand. J. Immunol. 93 (1), e12949. doi:10.1111/sji.12949

Zhu, X., Bührer, C., and Wellmann, S. (2016). Cold-inducible Proteins CIRP and RBM3, a Unique Couple with Activities Far beyond the Cold. Cell. Mol. Life Sci. 73 (20), 3839-3859. doi:10.1007/s00018-016-2253-7

Zhu, X., Yan, J., Bregere, C., Zelmer, A., Goerne, T., Kapfhammer, J. P., et al. (2019). RBM3 Promotes Neurogenesis in a Niche-dependent Manner via IMP2-IGF2 Signaling Pathway after Hypoxic-Ischemic Brain Injury. Nat. Commun. 10 (1), 3983. doi:10.1038/s41467-019-11870-x

Conflict of Interest: The authors declare that the research was conducted in the absence of any commercial or financial relationships that could be construed as a potential conflict of interest.

Publisher's Note: All claims expressed in this article are solely those of the authors and do not necessarily represent those of their affiliated organizations, or those of the publisher, the editors and the reviewers. Any product that may be evaluated in this article, or claim that may be made by its manufacturer, is not guaranteed or endorsed by the publisher.

Copyright ( $2021 \mathrm{Liu}, \mathrm{Liu}, \mathrm{Hu}, \mathrm{Cao}, \mathrm{Lu}$, Yang, Lv, Lian, Xu and Li. This is an openaccess article distributed under the terms of the Creative Commons Attribution License (CC BY). The use, distribution or reproduction in other forums is permitted, provided the original author(s) and the copyright owner(s) are credited and that the original publication in this journal is cited, in accordance with accepted academic practice. No use, distribution or reproduction is permitted which does not comply with these terms. 